\title{
The Behaviour of 2169 Steel Under Uniaxial Stress and Uniaxial Strain Loading
}

\author{
G. Whiteman $^{1}$ - P. T. Keightley ${ }^{1}$ J. C. F. Millett ${ }^{1}$
}

Received: 12 April 2016/Accepted: 13 May 2016/Published online: 24 May 2016

(C) Crown Copyright 2016

\begin{abstract}
A series of plate impact and uniaxial stress compression experiments have been undertaken on 2169 steel, a nitrogen strengthened austenitic stainless steel. The shock experiments ranged from impact stresses of $3.7-17.8 \mathrm{GPa}$, recording the wave profiles of the shock and spall behaviour observed at the rear target surfaces. Target and impactor configurations were varied to observe the effects of tensile strain-rates achieved at spall planes. Spall strength was observed to vary linearly with impact stress and tensile strain-rate although was less rate sensitive than 300 series steels suggestive of an influence of the shock induced microstructure on void nucleation. A fourth power relationship between strain-rate in the shock front and shock stress was observed similar to many other materials. The linear coefficient A relating the two is discussed in terms of dislocation mobility. Uniaxial stress compression experiments were undertaken on two grain sizes of the same material at a range of strain-rates from $\sim 10^{-4}$ to $10^{3} \mathrm{~s}^{-1}$. The data is consistent with other published data on 2169 steel showing a clear grain-size dependence on flow stress and higher flow stresses than other common austenitic steels.
\end{abstract}

Keywords 2169 steel $\cdot$ Spall $\cdot$ Shock $\cdot$ Wave profile SHPB · Strain-rate

\footnotetext{
G. Whiteman

glenn.whiteman@awe.co.uk

1 AWE, Aldermaston, Reading RG7 4PR, UK
}

\section{Introduction}

The regular presence of studies of stainless steel in research journals is testament to its ongoing importance in a wide variety of industries for a myriad of applications. In particular the dynamic deformation of steels has been studied for applications in vehicle crashworthiness, reactor containment and foreign object damage amongst many others. The current research focuses on 2169 stainless steel (21\% $\mathrm{Cr}, 6 \% \mathrm{Ni}, 9 \% \mathrm{Mn}$, balance $\mathrm{Fe}$ ), a nitrogen strengthened alloy which is less expensive than the more common stainless alloys due to its lower nickel content.

For true predictive capabilities of materials' response under dynamic loads the strength and material models used within hydrocode simulations are regularly improved to embrace a greater degree of physics. Multi-scale computational models which link physical mechanisms from the atomic to the polycrystalline scales offer perhaps the most promising future to a comprehensive physics based modeling of complex dynamic events. These types of models are currently reasonable and practicable for pure materials with relatively simple crystal structures, however for an alloy system the accurate determination of inter-atomic potentials and the choice of and application of those potentials for molecular dynamics simulations is very challenging. As such for materials like steels precisely measured materials effects need to be included in a more empirical way at the continuum level.

There have been a number of previous research papers presented on 2169 and similar alloys investigating the Hugoniot Elastic Limit (HEL-yield strength under onedimensional strain) [1-3], the shock Hugoniot [2-6] and dynamic spall strength (tensile stress in one-dimensional strain at which failure occurs) [1, 7]. Most recently Furnish et al. [3] published results of intricate planar impact 
experiments whereby they were able to estimate dynamic strength under compression using carefully controlled shock, reshock, and release velocimetry data. The yield strength in those experiments was determined to be $\sim 1.4 \mathrm{GPa}$ at $13 \mathrm{GPa}$ impact stress which compares favourably with the initial $\sim 1.7 \mathrm{GPa}$ value at $10 \mathrm{GPa}$ impact stress determined from lateral manganin stress gauge data on the same material batch as discussed within this paper [2]. Shock recovery experiments were undertaken by Hills and Rack [8] to investigate the shock deformed microstructure of 2169 in the range 2.5-60 GPa, observing that the variation in mechanical behaviour of the post-shocked specimens could be correlated to changes in microstructure such as the formation of coplanar dislocation arrays, stacking faults, deformation twins and martensite. Brusso [9] also investigated the recovered microstructures of shocked samples although using much shorter pulse durations noting that dislocation density appeared to saturate faster than other low stacking fault energy materials. A number of lower strain-rate studies have also been published [10-13] where the authors studied the true stress versus true strain response of 2169 under uniaxial stress compression, demonstrating the strain-rate sensitivity of flow stress over the strain-rate range of $10^{-4}$ to $10^{4} \mathrm{~s}^{-1}$.

In this paper we present a range of measured experimental data from quasi-static to shock loading and offer some observations regarding the trends seen and their relation to some microstructural deformation mechanisms.

\section{Materials}

Stainless steel 2169 is an alloy which uses the austenite stabilizing elements manganese and nitrogen to replace some of the nickel in the more common austenitic steels. Three batches of nominally the same material were obtained for the current study. Material A and B were supplied by All Metals and Forge, Parsippany, NJ, USA and Material $\mathrm{C}$ was supplied by Hempel Special Metale Ltd., UK. Material A was supplied in a $4^{\prime \prime}$ diameter bar, hot worked at $\sim 1090{ }^{\circ} \mathrm{C}$ then solution annealed at $\sim 1063{ }^{\circ} \mathrm{C}$. Materials B and $\mathrm{C}$ were supplied in 0.5 and $3.5^{\prime \prime}$ diameter bars, both solution annealed at $\sim 1063{ }^{\circ} \mathrm{C}$. The chemical composition of the batches is given in Table 1. Materials A and B were from the same stock but Material A had a larger average grain size $(100 \mu \mathrm{m})$ than Material B $(30 \mu \mathrm{m})$ (grain size measurements do not include annealing twins). Material $\mathrm{C}$, with an average grain-size of $\sim 100 \mu \mathrm{m}$ (discounting annealing twins) was chemically similar, with the only notable variations the $\sim 0.26 \mathrm{wt} \%$ of both copper and molybdenum.
Table 1 Chemical composition of SS2169 materials used in this study as supplied by manufacturers (in wt \%)

\begin{tabular}{lll}
\hline Element & Material A and B & Material C \\
\hline $\mathrm{Al}$ & - & $<0.01$ \\
$\mathrm{C}$ & 0.02 & 0.022 \\
$\mathrm{Co}$ & - & 0.06 \\
$\mathrm{Cr}$ & 19.56 & 19.79 \\
$\mathrm{Cu}$ & - & 0.27 \\
$\mathrm{Fe}$ & Balance & Balance \\
$\mathrm{Mn}$ & 8.56 & 8.86 \\
$\mathrm{Mo}$ & - & 0.26 \\
$\mathrm{~N}$ & 0.31 & 0.31 \\
$\mathrm{Nb}$ & - & 0.03 \\
$\mathrm{Ni}$ & 6.62 & 6.44 \\
$\mathrm{P}$ & 0.023 & 0.024 \\
$\mathrm{~S}$ & 0.003 & 0.001 \\
$\mathrm{Si}$ & 0.35 & 0.26 \\
$\mathrm{Sn}$ & - & 0.009 \\
$\mathrm{Ti}$ & - & $<0.01$ \\
$\mathrm{~V}$ & - & 0.04 \\
$\mathrm{~W}$ & - & $<0.05$ \\
\hline
\end{tabular}

The microstructure of each of the materials was investigated using electron back scatter diffraction (EBSD). Typical orientation maps and their respective inverse pole figures are shown in Fig. 1a, b, c for materials A, B and C respectively. A large number of annealing twins are evident in all three of the images as expected for a relatively low stacking fault energy (SFE) material. The SFE of this grade of material has been measured by previous researchers to be $\sim 41 \mathrm{~mJ} / \mathrm{m}^{2}$ [14]. Annealing twins are present in approximately $75 \%$ of the grains and account for around $45 \%$ of the sampled areas. The resultant texture analysis indicates a close to random texture ( $\sim$ two times random) for materials A and B (Fig. 1a, b) and a very mild texture ( $\sim$ six times random) for material $\mathrm{C}$ as shown in Fig. 1c. All materials exhibited an approximately equiaxed grain structure.

The physical properties of all materials have been measured and the details are provided in Table 2. Sound speed measurements were made via pulse echo techniques using $5 \mathrm{MHz}$ transducers in longitudinal and shear modes. The ultimate tensile strength (UTS) and yield strength (Y) were supplied by the manufacturers.

\section{Experimental}

Experiments were undertaken over a range of loading conditions for this research, from quasi-static compression using an Instron 5584 machine and split Hopkinson 
(a)

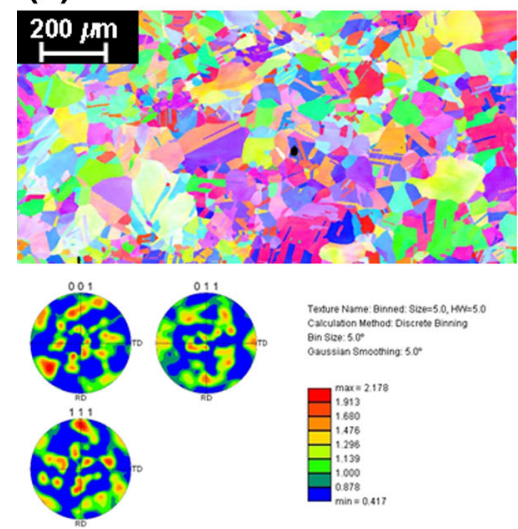

(b)

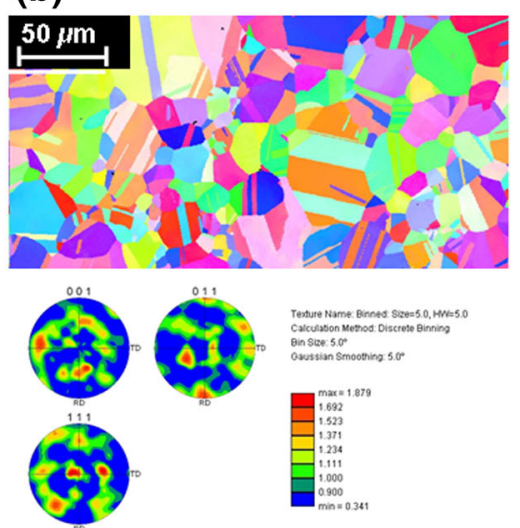

(c)

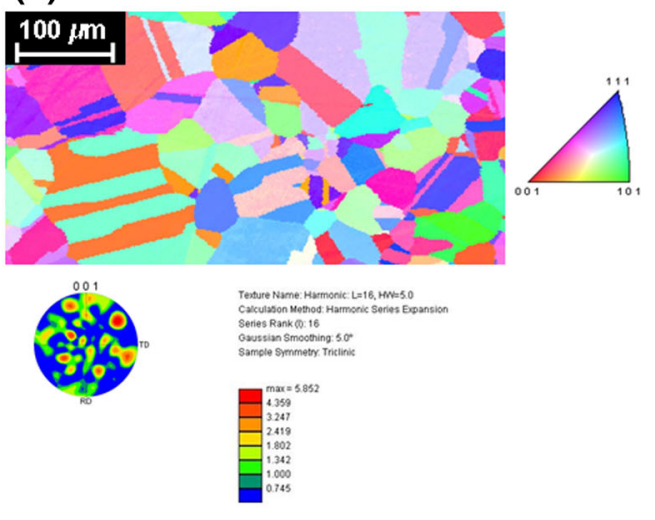

Fig. 1 EBSD orientations maps and respective inverse pole figures for the 2169 steel sample materials with the image normal perpendicular to the loading direction for a material A, b material B and $\mathbf{c}$ material C. Note that only one orientation pole figure was produced for material C

Table 2 Physical properties of the 2169 steel materials

\begin{tabular}{llllllll}
\hline $\begin{array}{l}\text { SS2169 material } \\
\text { designation }\end{array}$ & $\begin{array}{l}\text { Density, } \rho_{0} \\
\left(\mathrm{~g} / \mathrm{cm}^{3}\right)\end{array}$ & $\begin{array}{l}\text { Longitudinal sound } \\
\text { speed, } \mathrm{c}_{\mathrm{L}}(\mathrm{mm} / \mu \mathrm{s})\end{array}$ & $\begin{array}{l}\text { Shear sound speed, } \\
\mathrm{c}_{\mathrm{S}}(\mathrm{mm} / \mu \mathrm{s})\end{array}$ & $\begin{array}{l}\text { Bulk sound speed, } \\
\mathrm{c}_{\mathrm{B}}(\mathrm{mm} / \mu \mathrm{s})\end{array}$ & $\begin{array}{l}\text { Poisson's } \\
\text { ratio, } v\end{array}$ & $\begin{array}{l}\text { UTS } \\
(\mathrm{MPa})\end{array}$ & $\begin{array}{l}\mathrm{Y}, 0.2 \% \\
\mathrm{strain}(\mathrm{MPa})\end{array}$ \\
\hline Material A & $7.75(0.01)$ & $5.69(0.01)$ & $3.15(0.01)$ & $4.38(0.023)$ & $0.279(0.003)$ & 724.6 & 405.4 \\
Material B & $7.76(0.01)$ & $5.75(0.03)$ & $3.16(0.01)$ & $4.44(0.049)$ & $0.284(0.006)$ & 737.7 & 442.6 \\
Material C & $7.818(0.022)$ & $5.732(0.027)$ & $3.133(0.008)$ & $4.446(0.036)$ & $0.287(0.011)$ & 698.4 & 346.8 \\
\hline
\end{tabular}

Measurement errors are in parentheses

pressure bar (SHPB) [15] up to plate impact [16]. The specific details are discussed below.

\section{Plate Impact Experiments}

The plate impact experiments were only performed on Materials $\mathrm{A}$ and $\mathrm{C}$ in this research; the small diameter of the Material B supply meant insufficient time in uniaxial strain would be available to achieve meaningful results. Experiments were performed on 50 and $70 \mathrm{~mm}$ bore single stage gas launchers at the Cavendish Laboratory, University of Cambridge [17] and AWE respectively. Experimental configurations consisted of symmetric impacts of flat (to within $5 \mu \mathrm{m}$ ) plates at varied impact stresses from $\sim 4$ to $18 \mathrm{GPa}$. Impactor thicknesses of $\sim 1,2$ and $3 \mathrm{~mm}$ and target thicknesses of $\sim 4$ and $6 \mathrm{~mm}$ were chosen to investigate pulse duration/tensile strain-rate effects on the release/spall behaviour and wave evolution through the targets. The rear surface laser velocimetry was undertaken using VISAR (velocity interferometry system for any reflector) [18] or HetV (heterodyne velocimetry) [19]. Velocity was measured on the sample free surface for both materials and through an additional lithium fluoride window for experiments on Material $\mathrm{C}$. The flyer plates were mounted on hollow polycarbonate sabots and were backed with PMMA for the experiments on material $\mathrm{C}$ to prevent the flyer bending during acceleration down the launcher barrel. A schematic representation of the experimental set up is shown in Fig. 2 while specific experimental details are included in Table 3.

\section{Uniaxial Stress Compression Experiments}

The quasi-static compression and SHPB experiments were performed at the University of Cambridge in the Department of Engineering and the Cavendish Laboratory

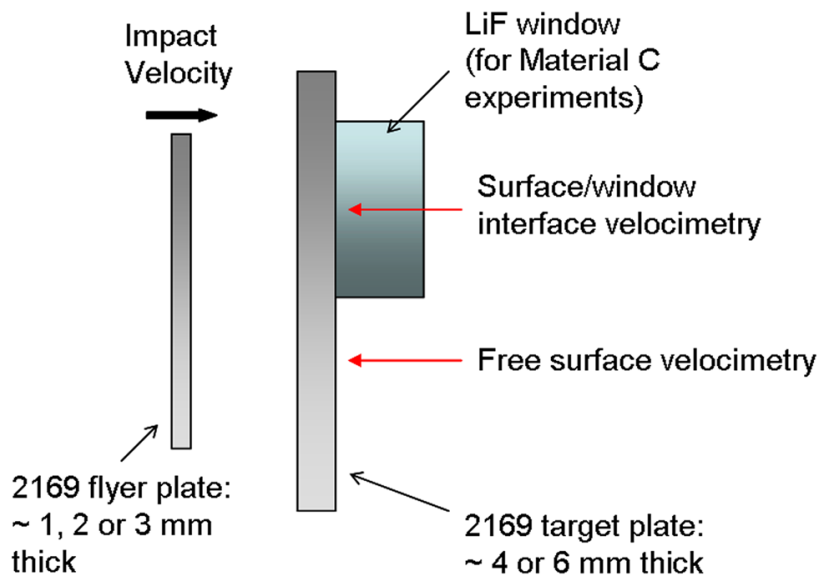

Fig. 2 Schematic of specimen and flyer plate geometry 
respectively. Cylindrical samples of approximately $3 \mathrm{~mm}$ length and $5 \mathrm{~mm}$ diameter were compressed in both cases. Eight samples of Material A and Material B were tested on the Instron machine over a range of strain-rates, $1.1 \times 10^{-4}$ to $1.8 \times 10^{-2} \mathrm{~s}^{-1}$, and time, load and extension used to produce true-stress versus true-strain plots for each of the samples. For the SHPB experiments, 12 samples of Material A and Material B were tested at a range of strain-rates from $0.5 \times 10^{3}$ to $1.2 \times 10^{3} \mathrm{~s}^{-1}$. Voltagetime records from bar mounted strain gauges have been used to produce true-stress versus true-strain data for each sample. Material $\mathrm{C}$ was not tested in these experiments as it formed part of a separate experimental programme where quasi-static data was not required.

\section{Results}

\section{Shock Experiments Waveforms}

Both free surface and windowed samples were part of this series. The free surface experiments allowed wave profiles to be obtained and analysed free from the uncertainties introduced by use of window materials and left the materials free to release and spall. The windowed samples allowed a more detailed interrogation of features in the elastic plastic transition which are otherwise confused by interactions of waves reflecting off the free surface (as no window is a perfect impedance match this is reduced rather than eliminated by the use of the window). Typical waveforms for these experiments are shown in Fig. 3 where the time base has been normalised to sample thickness to allow straightforward comparison of data from the varied sample thicknesses. Two traces from Furnish et al. [3] ( $\mathrm{a} \sim 1 \mathrm{~mm}$ thick impactor on 2 and $4 \mathrm{~mm}$ thick samples) have been included in Fig. $3 \mathrm{c}$ for comparison with 1 and $2 \mathrm{~mm}$ impactors on $\sim 4 \mathrm{~mm}$ thick samples from this research.

The data in the figure shows classic features of a two part loading front including a HEL (although this is not a clear elastic to plastic transition before the main shock rise), a stress (or particle velocity) plateau $\left(u_{\max }\right)$, release to a minimum $\left(u_{\min }\right)$ and spallation (in the case of the free surface samples). The shape of the curves is consistent in all the data, with faster rise times in the shock for higher stresses (Fig. 3a, b) and noticeably similar elastic-plastic release behavior when compared to Furnish et al. [3] (Fig. 3c). The elastic limit is not addressed in detail within this paper although the form and magnitude is similar between the materials tested in this work $(1.63 \pm 0.24 \mathrm{GPa})$, previously published stress gauge data in shock loading experiments on the same material [2] $(1.27 \pm 0.64 \mathrm{GPa})$ and data published by Furnish et al. [3] $(0.62-1.56 \mathrm{GPa})$. The Hugoniot of the stainless steel

Table 3 Configuration details for the plate impact experiments

\begin{tabular}{|c|c|c|c|c|c|c|}
\hline $\begin{array}{l}\text { Experiment } \\
\text { number }\end{array}$ & $\begin{array}{l}\text { Impact velocity } \\
(\mathrm{mm} / \mu \mathrm{s})\end{array}$ & $\begin{array}{l}\text { Hugoniot stress } \\
(\mathrm{GPa})\end{array}$ & $\begin{array}{l}\text { Flyer and sample } \\
\text { material }\end{array}$ & $\begin{array}{l}\text { Flyer thickness } \\
(\mathrm{mm})\end{array}$ & $\begin{array}{l}\text { Sample thickness } \\
(\mathrm{mm})\end{array}$ & Diagnostics \\
\hline $1 \mathrm{~A}$ & $0.514(0.003)$ & 9.66 & SS2169 A & $1.95(0.01)$ & $3.95(0.01)$ & VISAR, free surface \\
\hline $2 \mathrm{~A}$ & $0.696(0.004)$ & 13.45 & SS2169 A & $1.95(0.01)$ & $3.95(0.01)$ & VISAR, free surface \\
\hline $3 \mathrm{~A}$ & $0.515(0.003)$ & 9.62 & SS2169 A & $2.96(0.01)$ & $3.95(0.01)$ & VISAR, free surface \\
\hline $4 \mathrm{~A}$ & $0.696(0.004)$ & 13.50 & SS2169 A & $2.95(0.01)$ & $3.95(0.01)$ & VISAR, free surface \\
\hline $5 \mathrm{~A}$ & $0.373(0.002)$ & 6.86 & SS2169 A & $1.96(0.01)$ & $3.95(0.01)$ & VISAR, free surface \\
\hline $6 \mathrm{~A}$ & $0.513(0.003)$ & 9.60 & SS2169 A & $0.96(0.01)$ & $3.95(0.01)$ & VISAR, free surface \\
\hline $7 \mathrm{~A}$ & $0.892(0.005)$ & 17.75 & SS2169 A & $1.95(0.01)$ & $3.95(0.01)$ & VISAR, free surface \\
\hline $8 \mathrm{~A}$ & $0.698(0.004)$ & 13.37 & SS2169 A & $0.96(0.01)$ & $3.95(0.01)$ & VISAR, free surface \\
\hline $1 \mathrm{C}$ & $0.216(0.001)$ & 3.72 & SS2169 C & $3.039(0.005)$ & $6.029(0.005)$ & $\begin{array}{l}\text { Het } V \text {, free surface and } \\
\text { windowed }\end{array}$ \\
\hline $2 \mathrm{C}$ & $0.392(0.001)$ & 7.01 & SS2169 C & $3.043(0.005)$ & $6.03(0.005)$ & $\begin{array}{l}\text { HetV, free surface and } \\
\text { windowed }\end{array}$ \\
\hline $3 \mathrm{C}$ & $0.544(0.001)$ & 10.04 & SS2169 C & $3.036(0.005)$ & $6.023(0.005)$ & $\begin{array}{l}\text { Het } V \text {, free surface and } \\
\text { windowed }\end{array}$ \\
\hline $4 \mathrm{C}$ & $0.694(0.001)$ & 13.20 & SS2169 C & $3.035(0.005)$ & $6.028(0.005)$ & $\begin{array}{l}\text { HetV, free surface and } \\
\text { windowed }\end{array}$ \\
\hline $5 \mathrm{C}$ & $0.800(0.001)$ & 15.28 & SS2169 C & $3.034(0.005)$ & $6.024(0.005)$ & $\begin{array}{l}\text { HetV, free surface and } \\
\text { windowed }\end{array}$ \\
\hline $6 \mathrm{C}$ & $0.657(0.001)$ & 12.46 & SS2169 C & $3.034(0.005)$ & $6.022(0.005)$ & $\begin{array}{l}\text { HetV, free surface and } \\
\text { windowed }\end{array}$ \\
\hline
\end{tabular}

Measurement errors are in parentheses 

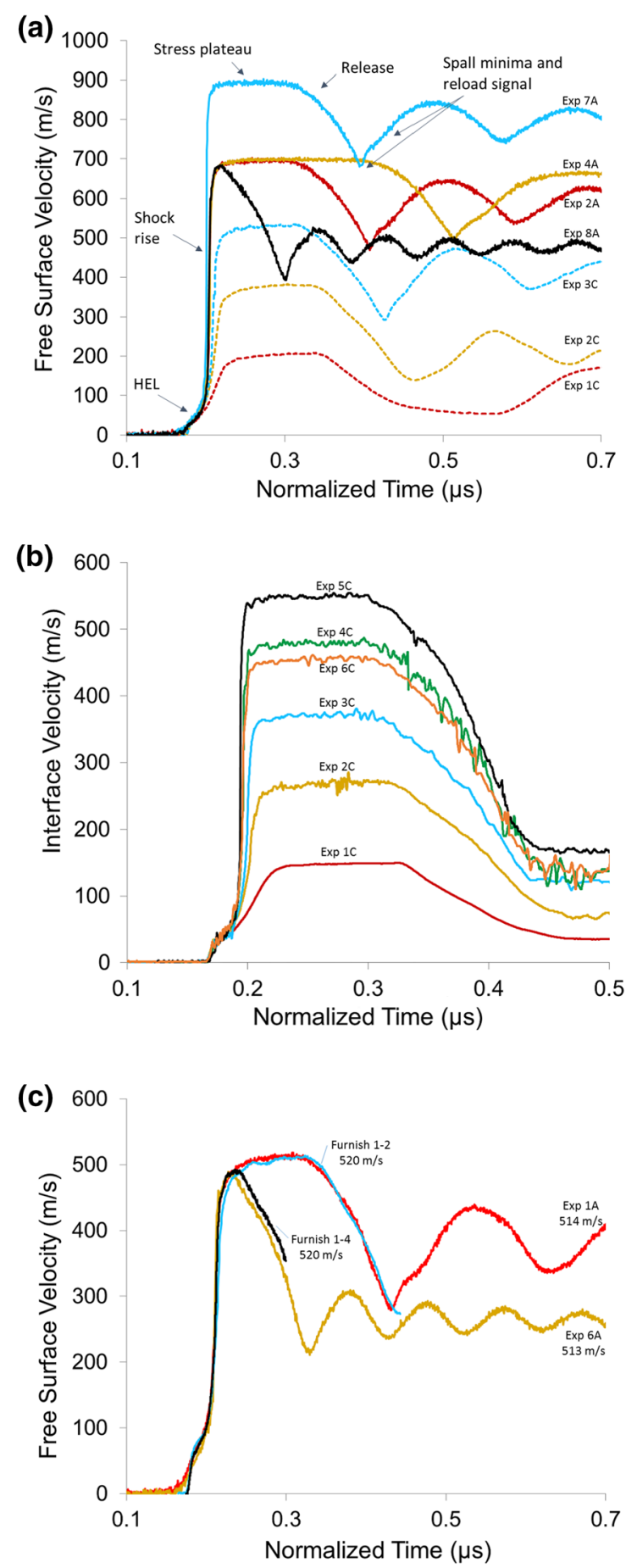

Fig. 3 a Typical free surface velocity traces and $\mathbf{b}$ windowed sample velocity traces. c Comparison of typical wave profiles from current research and Furnish et al. [3]

material from these experiments has been determined from the waveforms recorded using the known velocity of the elastic wave $\left(c_{L}\right)$ and the target thicknesses. The Hugoniot is presented in Fig. 4 in both pressure versus particle velocity and shock velocity versus particle velocity forms including previously published data $[2,3,5,6]$. The linear fit of shock velocity $\left(U_{S}\right)$ versus particle velocity $\left(u_{p}\right)$, $\mathrm{U}_{\mathrm{S}}=\mathrm{c}_{0}+\mathrm{S} \cdot \mathrm{u}_{\mathrm{p}}$, indicated in the figure is consistent with that presented by Furnish et al. [3] with the constants established as $c_{0}=4.477$ and $S=1.465$.

\section{Spall}

For the free surface experiments, in all but the lowest impact stress case, the steel failed under dynamic tension (spallation) caused by interacting release waves from the rear of the flyer and the target free surface. The one-dimensional failure stress $\left(\sigma_{\mathrm{F}}\right)$ can be calculated from the rear free surface velocity waveform using the features indicated in Fig. 3a, accounting for variations in impedance [20],

$\sigma_{F}=\rho_{0}\left(u_{\max }-u_{F}\right)\left[c_{0}+S\left(u_{\max }+u_{F}\right)\right]$.

where
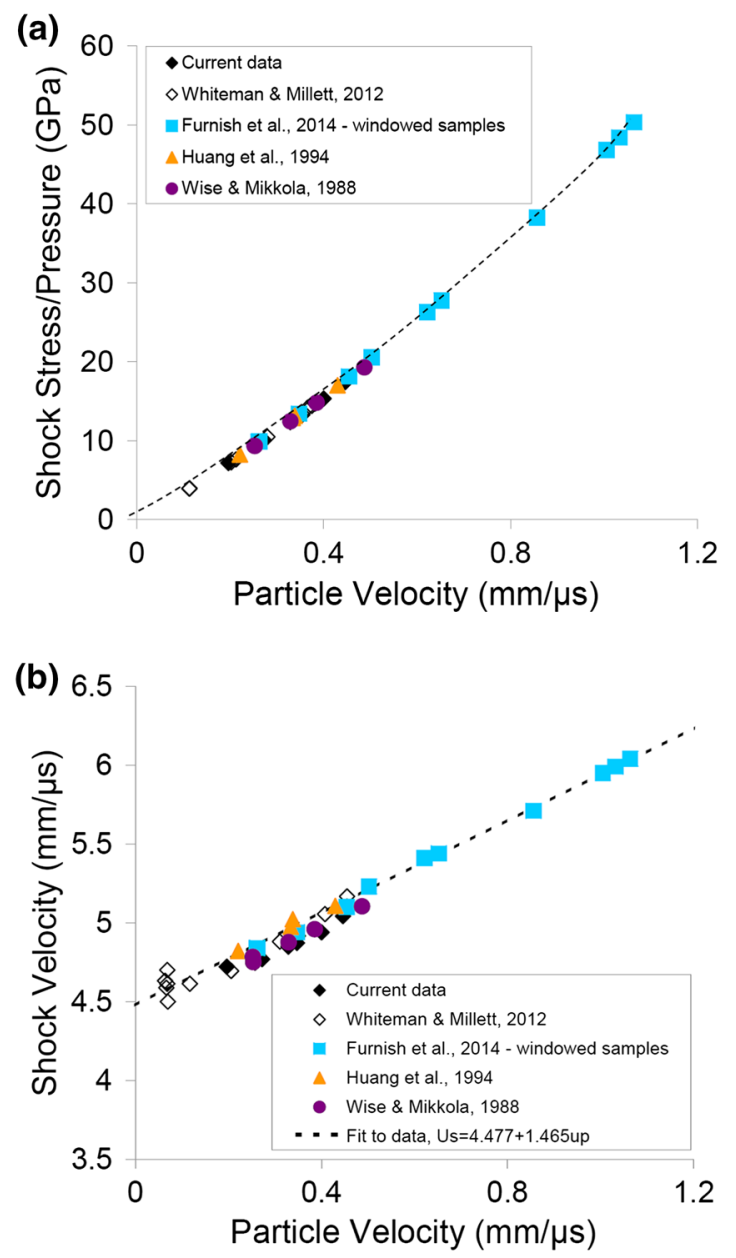

Fig. 4 Hugoniot plots for current and previous experiments [2, 3, 5, $6]$ in the planes of a pressure versus particle velocity and b shock velocity versus particle velocity 


$$
\begin{aligned}
u_{F}= & \frac{1}{2}\left[-\left(\frac{c_{0}}{S}\right)+\left\{\left(\frac{c_{0}}{S}\right)^{2}+2\left[\left(\frac{c_{0}}{S}\right)\left(u_{\max }+u_{\min }\right)\right.\right.\right. \\
& \left.\left.\left.+\left(u_{\max }^{2}+u_{\min }^{2}\right)\right]\right\}^{1 / 2}\right]
\end{aligned}
$$

However, it has also been pointed out by Romanchenko and Stepanov [21] that the reload part of the signal is attenuated as it travels through the spalled scab, hence the actual spall strength [22], $\sigma_{\text {spall }}$ is,

$\sigma_{\text {spall }}=\sigma_{F}+\Delta \sigma$,

where $\Delta \sigma$, the attenuated part of the spall signal is,

$\Delta \sigma=\frac{h}{2} \frac{d P}{d t}\left(\frac{1}{c_{B}}-\frac{1}{c_{L}}\right)$,

where $\mathrm{h}$ is the thickness of the spalled scab (in these experiments, assumed to be equal to the flyer thickness as these were symmetric impact geometries) and $d P / d t$ is the rate at which the material is led into tension. Following Chhabildas et al. [22] $d P / d t$ has been approximated to $\sigma_{F} /$ $t$ where $t$ is the duration of the pull back signal. The results have been plotted against impact stress in Fig. 5 .

In Fig. 5 it can be seen that the spall strength of 2169 increases gradually with increased shock stress over the regime studied. The data from this research is in distinct bands separated as a result of different impactor thickness and hence the dynamic tensile strain-rate. Very little spall data exists for this type (or other types) of austenitic stainless steel. A single spall measurement has been derived from the research of $\mathrm{Gu}$ et al. [1] and is included in the data set shown. This room temperature experiment on 2169 steel is clearly consistent with the current data. Spall data on other austenitic steels, 316L [23-25] (including unpublished gauge data taken and provided by Gray,

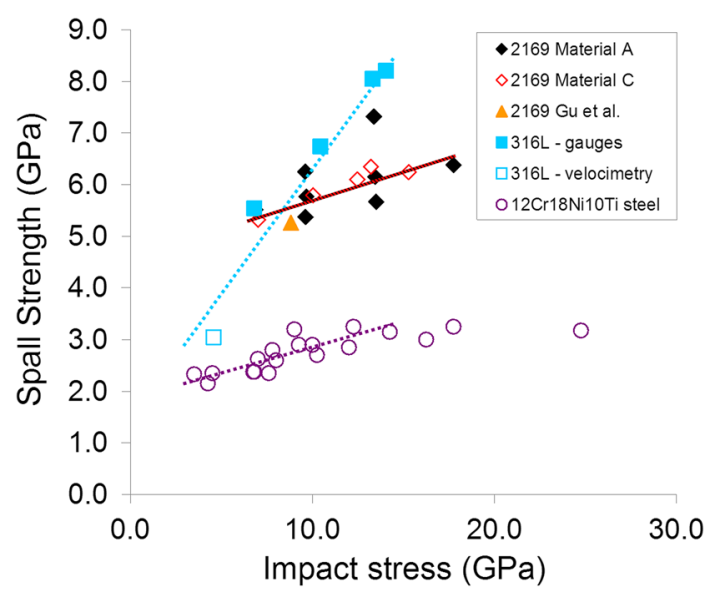

Fig. 5 Spall strength of stainless steel 2169 as a function of impact stress. Data from current research, Gu et al. [1], Gray et al. [23-25] and Pavlenko et al. [26] are included with trend lines to aid discussion
Bourne and Millett) and 12Cr18Ni10Ti [26] (a high alloy steel used in the construction of nuclear reactors) are also shown in the figure. Despite the prevalence of the 'classic' engineering stainless steels such as 316 and 304, a thorough investigation could not be found in the literature. The majority of the $316 \mathrm{~L}$ data shown $[23,25]$ has been converted from rear surface window mounted stress gauge data and as such a significant error has been associated with the derived spall strength from this conversion. However, despite the uncertainty in this data, when combined with the single rear free surface velocimetry measurement [24] it appears to indicate an initially lower spall strength but a significantly greater influence of impact stress suggestive of higher strain-rate sensitivity. The data set derived for 12Cr18Ni10Ti steel [26] shows a much weaker tensile strength but an initial similar sensitivity of spall strength to impact stress. Its spall strength then appears to reach a constant level above $\sim 12 \mathrm{GPa}$ impact stress, a feature not apparent for the other steels in the data presented.

The spall behaviour of materials is not a simple process, the impact stress and pulse duration create a microstructure evolved from the initial material which is subsequently led into tension at a tensile strain-rate determined by the material and configuration employed. Given the variety of target and flyer configurations and the known effects of strain-rate on strength measurements [27, 28], a convenient way to present and study spall strength is as a function of the dynamic tensile strain-rate (normalised to target thickness) as shown in Fig. 6. In this case the tensile strainrate is defined as,

$\dot{\varepsilon}_{r}=\frac{d u_{f s} / d t}{2 U_{S}}$,

where $d u_{f s} / d t$ is the maximum gradient in the release portion of the free surface velocity trace.

It can be observed from the data that 2169 exhibits a consistent linear variation of spall strength with tensile strain-rate. This suggests that pulse duration effects of spall strength are less significant in this alloy over the impact stress range investigated.

\section{Quasi-static and intermediate strain rate compression tests}

The lower strain-rate uniaxial stress compression experiments were undertaken on the same material as tested in the shock experiments (Material A) and a smaller grain size material manufactured from the same stock material (Material B). Typical true stress $(\sigma)$ versus true strain $(\varepsilon)$ curves are shown in Fig. 7 for samples of the 2169 loaded at strain-rates of $\sim 10^{3} \mathrm{~s}^{-1}$.

The figure shows an increase in yield and flow stress for the smaller grain-sized materials but a very similar degree 


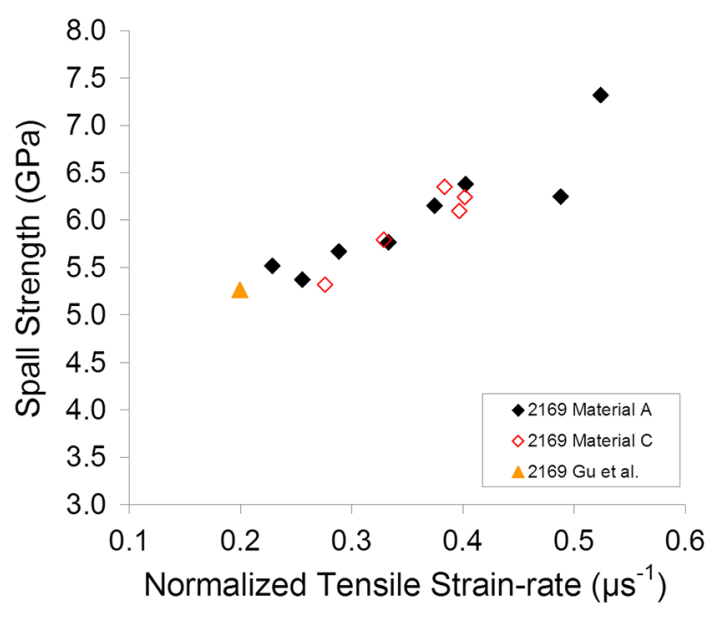

Fig. 6 Spall strength of stainless steel 2169 as a function of tensile strain-rate normalized to target thickness. Data from current research and $\mathrm{Gu}$ et al. [1] is shown

of work hardening (increase in flow stress with strain). The flow stress at $10 \%$ strain determined from these data is $\sim 930 \mathrm{MPa}$ for the larger grain-size material and $\sim 1030 \mathrm{MPa}$ for the smaller grain size material indicative of a Hall-Petch [29] type effect. At lower strain-rates the equivalent flow stresses are of the order 670 and $760 \mathrm{MPa}$ for the large and small grain-size materials respectively. The data is presented in Fig. 8 compared to data derived on from published literature on 2169 steels [12, 13], a similar nitrogen strengthened steel [30] and two classic engineering steels, 304L [13] and 316L [13, 25, 31].

In general it is clear that all of the steels exhibit a similar increase in flow stress with strain-rate despite the obvious lower flow stresses observed in the 300 series steels and the clear effect due to grain size observed in these experiments.

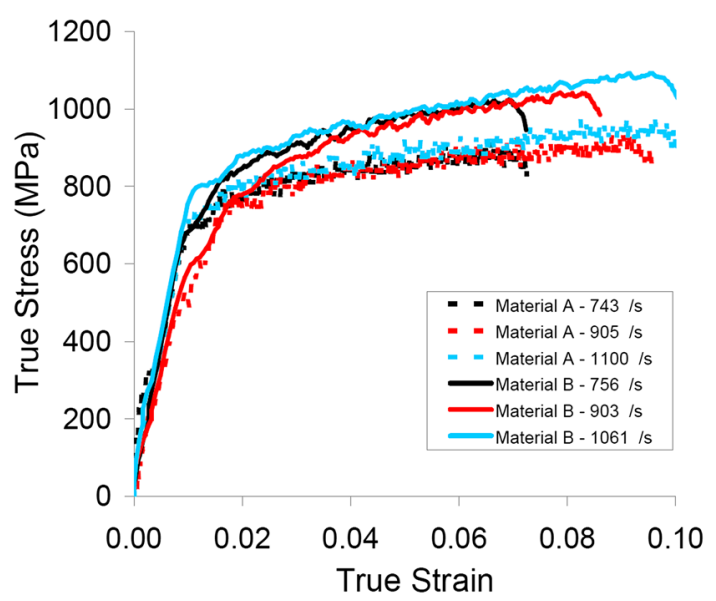

Fig. 7 True stress- true strain curves for large and small grain-size 2169 samples loaded via SHPB in compression

\section{Discussion}

The waveforms presented in the previous section provide a consistent picture of the behaviour of 2169 steel from this research and when compared to the research of Furnish et al. [3]. Stainless steel is a useful engineering material for which more accurate predictive computational models could provide significant benefits. Empirical relationships regarding dynamic deformation and the mechanisms at play under dynamic impact conditions can assist in this. Previous research [32] has noted that a fourth power relation exists between the compressive strain-rate $(\dot{\varepsilon})$ observed at the free surface of a shocked metal sample and the stress achieved $\left(\sigma_{x}\right)$, such that,

$\dot{\varepsilon}=A \sigma_{x}^{4}$,

where the coefficient $A$ is a material dependent parameter. This relation is considered valid for data where the shock waves can be considered steady, i.e. discounting the points where the Bland number (a dimensionless number defined by Swegle and Grady [32] as the ratio of sample thickness to steady-wave propagation distance as defined by Bland [33]) is less than unity. Previous research has suggested that the fourth power relation is related to dissipative mechanisms at the shock front, including dislocation activity in crystalline materials [34] or more specifically the nucleation, density and velocity of dislocations [35] and the power law pressure dependence of the density of geometrically necessary dislocations generated at the shock wave front in combination with the rate of viscous motion of dislocations [36]. As the fourth power rule appears to be largely universal, particularly for metallic materials, the division of data from different materials appears via the

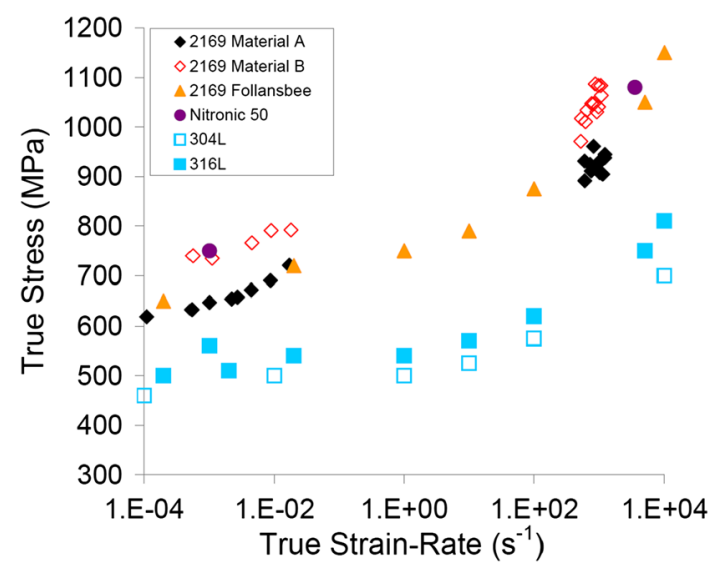

Fig. 8 Flow stress at $10 \%$ strain determined from this research and other austenitic stainless steels; 2169 from Follansbee et al. [12, 13], Nitronic 50 from Guo and Nemat-Nasser [30], 304L from Follansbee [13] and 316L from Follansbee [13], Sencer et al. [25] and Gray et al. [31] 
coefficient $A$. Malygin et al. [36] related $A$ to the inverse of the dislocation viscous drag coefficient however they were unable to match the theory to data within published limits on the values of the coefficient. Very little else has been discussed in the literature about the origins of A although it seems reasonable, as has been hypothesized by Millett et al. [37], that A could also be considered to be related to deformation mechanisms at play in shocked materials, particularly a material's ability to accommodate plasticity via dislocation generation and motion. In that work, it was noted that the data presented by Grady [34] was in two main groups; higher values of A were displayed by copper and aluminium, with materials such as beryllium, vanadium, uranium and iron having lower values, with molybdenum having the lowest value of $A$ of all. Millett et al. [37] went on to suggest that that this was a manifestation of dislocation generation and mobility. Copper and aluminium, as moderate to high stacking fault energy fcc metals, display a high degree of dislocation motion and generation during shock loading [38, 39]. The deformation mechanisms of the second group are more varied, but iron, molybdenum and uranium have been shown to deform under shock loading conditions via twinning [40-43] whilst beryllium (hcp) and uranium (orthorhombic) both possess low symmetry unit cells, which will also reduce the ability of these materials to deform by simple dislocation generation.

To determine the relation in Eq. 6 for 2169 we have followed the methodology of Grady [34], where we have taken into account the elastic response of the material as well, using the stress jump $(\Delta \sigma)$ between the elastic limit and the final stress amplitude carried by the imposed shock front. The strain-rate was determined by differentiating the particle velocity (half of the free surface velocity) versus time traces to find the maximum rate of change on the rising part of the shock front, and dividing by the shock velocity, correcting for the particle velocity carried by the elastic wave $\left(\mathrm{u}_{\mathrm{e}}\right)$,

$\dot{\varepsilon}=\frac{d u_{p}}{d t} \frac{1}{U_{S}-u_{e}}$

The results are presented in Fig. 9.

As can be observed in the plot the data from 2169 from this research and other researchers [3, 6] agrees with the approximate fourth power relation, with the material coefficient $\mathrm{A}$ determined as $1.8 \times 10^{-4}$. The data are compared to those presented by Grady [34] and Millett et al. [37] in Fig. 10 (reversing the axes).

Observe that the data for 2169 clearly lies with the group with a lower value of $\mathrm{A}$; uranium, beryllium, iron and vanadium. Whilst 2169 is a single phase alloy, it has a low stacking fault energy $\left(41 \mathrm{~mJ} / \mathrm{m}^{2}\right.$ [14]), resulting in a wide separation of partial dislocations. This will further result in a reduction in dislocation mobility to the point where twinning is favoured [44]. It is therefore not surprising that the data for 2169 is associated with that of uranium and iron etc., rather than the fcc copper and aluminium. This data gives further credence to the hypothesis made in a previous publication [37] that A is strongly affected by dislocation mobility. While high quality physically based strength models used in Hydrocode simulations are typically viscous models themselves, i.e. they include rate dependence as a function of dislocation velocity and density, other simple and widely used strength models could benefit from this empirical observation by tuning material models via this parameter presumably in a way similar to an artificial viscosity but with more physical credence.

Addressing the spall data presented in Figs. 5 and 6 it was observed that the spall strength of 2169 increases consistently with impact stress and tensile strain-rate but that for $316 \mathrm{~L}$ there is an inferred higher rate effect. From the limited comparison possible from the lower strain-rate compression data presented in Fig. 8 there is an indication that the rate sensitivity between the materials was similar. This suggests that the differences in the observed spall behaviour are more likely to be manifestations of the effect of tension on the induced microstructures. In the range of shock stresses achieved in the current research (i.e. $<20 \mathrm{GPa}$ ) Hills and Rack [8] observed a linear increase in residual tensile yield strength from shock recovered samples of 2169 steel. They also observed deformation mechanisms being a mixture of coplanar dislocation arrays, stacking faults and deformation twinning whereas above $20 \mathrm{GPa}$ it was primarily deformation twinning (martensite phase was only observed in samples shock recovered at and above $30 \mathrm{GPa}$ ). The microstructures induced around voids

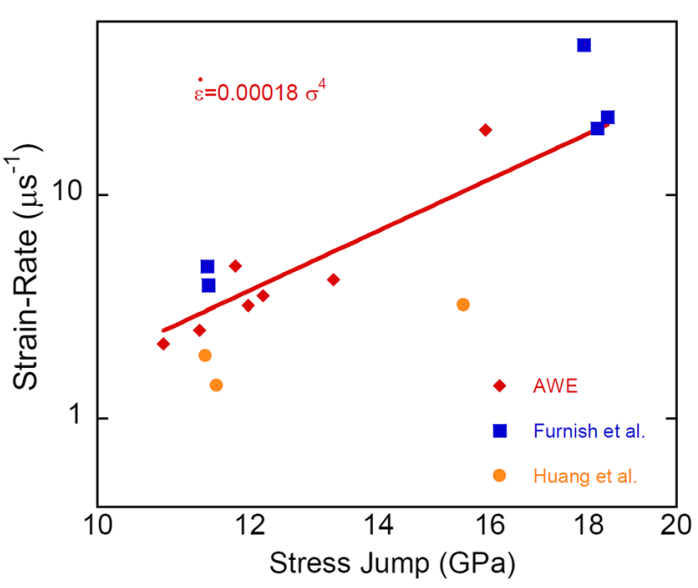

Fig. 9 Stress jump between elastic limit and maximum shock amplitude versus strain-rate for 2169 steel from this research, Furnish et al. [3] and Huang et al. [6] according to Swegle and Grady [32] and Grady [34] 


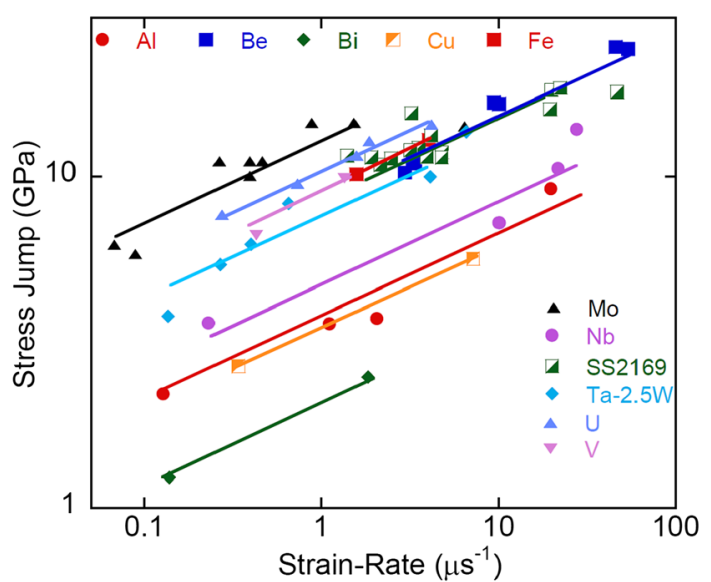

Fig. 10 Strain-rate versus stress jump between elastic limit and maximum shock amplitude for various materials. Data from current research, Grady [34] and Millett et al. [37]

in spall recovery experiments have not been reported on for either 2169 or $316 \mathrm{~L}$ to the authors' knowledge however clearly this information, e.g. whether the twin boundaries induced in the low stacking fault energy 2169 steel are a preferential site for nucleation of voids, would be valuable in the future.

The results discussed in this paper for 2169 have focussed on providing dynamic deformation data for this specific useful alloy and its comparison with other common austenitic stainless steels. However it is important to note that changes in microstructure in chemically identical steels can have wide ranging effects particularly on spall response which is a complex integrated problem. This can be aptly demonstrated in recent advances in the field of additive manufacturing (AM) such as the work of Gray et al. [24] where the authors have shown large differences in the dynamic behaviours can be created when one compares $316 \mathrm{~L}$ steel in wrought, AM and AM followed by heat treatment varieties.

\section{Conclusions}

The current study on the dynamic response of 2169 stainless steel has provided a useful body of evidence into the behaviour of this material over a range of strain-rates and its comparison to the more common austenitic steels. The data in this research was shown to be consistent to that previously published for other $2169[1-7,13]$ and similar nitrogen strengthened steels [30]. The flow stress of 2169 steel is significantly higher than the other austenitic stainless steels under low to intermediate strain-rate compression and it also displays a linear dependence of flow stress and spall strength with compressive and dynamic tensile strain-rates respectively. Rate effects are not noticeably more significant compared to other austenitic steels when testing under uniaxial stress however in the higher rate, uniaxial strain data the spall strength appears to be less rate sensitive than 300 series steels suggestive of an influence of the shock induced microstructure on void nucleation. It can be observed that when looking at the Swegle-Grady relation [32] between stress and strain-rate that materials appear to divide themselves into two distinct groups, distinguished largely by their dislocation mobility. The 2169 steel in this case fits with the group including iron, beryllium and uranium due to its low stacking fault energy rather than other fcc materials such as copper and aluminium. Future soft recovery experiments on 2169 steel are planned to investigate the roles of dislocation and twin based mechanisms of plasticity.

Acknowledgments The authors would like to acknowledge C.H. Braithwaite (Cavendish Laboratory, University of Cambridge) and D.J. Chapman (formerly of the same, now at the Institute of Shock Physics, Imperial College London) for their assistance in undertaking several of the experiments presented in this paper. We would also like to thank G.T. Gray III (Los Alamos National Laboratory) and M.D. Furnish (Sandia National Laboratory) for kindly providing access to some of the raw data used and referenced within this paper. Finally we would like to acknowledge V. Durrant of AWE for his invaluable manufacturing advice and skills. (c) British Crown Owned Copyright 2016/AWE. Published with permission of the Controller of Her Britannic Majesty's Stationery Office. "This document is of United Kingdom origin and contains proprietary information which is the property of the Secretary of State for Defence. It is furnished in confidence and may not be copied, used or disclosed in whole or in part without prior written consent of Defence Intellectual Property Rights DGDCDIPR-PL-Ministry of Defence, Abbey Wood, Bristol, BS34 8JH, England."

\section{References}

1. Gu Z, Jin X, Gao G (2000) Shock response of stainless steel at high temperature. J Mater Sci 35(9):2347-2351

2. Whiteman G, Millett JCF (2011) Shear stress measurements in stainless steel 2169 under 1D Shock loading. Exp Mech 52(3):265-273

3. Furnish MD, Alexander CS, Brown JL, Reinhart WD (2014) 2169 steel waveform measurements for equation of state and strength determination. J Appl Phys 115:033511

4. Gust WH, Steinberg DJ, Young DA (1979) Hugoniot parameters to $320 \mathrm{GPa}$ for three types of steel. High Temp High Pressures 11:271-280

5. Wise JL, Mikkola DE (1987) Hugoniot and wave-profile measurements on shock-loaded stainless steel (21Cr-6Ni-9Mn). In: Proceedings of the SCCM conference, vol 20. American Institute of Physics, Melville

6. Huang S, Jin X, Li Z, Wang X, Guan K (1994) Experimental measurements of 21-6-9 stainless steel under dynamic loading. In: Proceedings of the SCCM conference. American Institute of Physics, Melville

7. Whiteman G, Bourne NK, Millett JCF (2009) Spall experiments on stainless steel 21-6-9 varying pulse lengths and longitudinal 
stress. In: Proceedings of the SCCM conference, American Institute of Physics, Melville

8. Hills CH, Rack HJ (1981) Effect of shock deformation on the residual strength and microstructure of Nitronic 40 stainless steel. Mater Sci Eng 51:231-239

9. Brusso JA, Mikkola DE, Bloom G, Lee RS, Vonholle W (1987) Use of electric gun experiments to study the shock deformation behaviour of 21-6-9 stainless steel. In: Proceedings of the SCCM conference, American Institute of Physics, pp 375-378

10. Kassner ME, Geantil P (2012) Yield stress of 21-6-9 stainless steel over very wide ranges of strain rates and temperatures. J Mater Eng Perform 21(1):69-73

11. Kassner ME, Breithaupt RD (1984) The yield stress of 21-6-9 stainless steel over a wide range of strain rate $\left(10^{-5}\right.$ to $\left.10^{4} \mathrm{~s}^{-1}\right)$ and temperature. In: Harding J (ed) Mechanical properties at high rates of strain. Institute of Physics, London, pp 47-54

12. Follansbee PS, Kocks UF, Regazzoni G (1985) The mechanical threshold of dynamically deformed copper and Nitronic 40. J Phys Colloq 46(C5):5-25

13. Follansbee PS (1985) High-strain-rate deformation of FCC metals and alloys. In: International conference on metallurgical applications of shock-wave and high-strain-rate phenomena, vol 28, pp 451-479

14. Schramm RE, Reed RP (1975) Stacking fault energies of seven commercial austenitic stainless steels. Metall Mater Trans A $6(8): 1345-1351$

15. Gray GT III (2000) Classic split-Hopkinson pressure bar testing. ASM International, Materials Park, pp 462-476

16. Davison L, Graham RA (1979) Shock compression of solids. Phys Rep 55(4):255-379

17. Bourne NK, Rosenberg Z, Johnson DJ, Field JE, Timbs AE, Flaxman RP (1995) Design and construction of the UK plate impact facility. Meas Sci Technol 6:1462-1470

18. Barker LM, Hollenbach RE (1972) Laser interferometer for measuring high velocities of any reflecting surface. J Appl Phys 43:4669

19. Strand OT (2006) Compact system for high-speed velocimetry using heterodyne techniques. Rev Sci Instrum 77:083018

20. Gathers GR (1994) Selected topics in shock wave physics and equation of state modeling. World Scientific, Singapore

21. Romanchenko VI, Stepanov GV (1980) Dependence of the critical stresses on the loading time parameters during spall in copper, aluminum, and steel. Zhur Prik Mekh Tekh Fiz 4:141

22. Chhabildas LC, Barker LM, Asay JR, Trucano TG (1990) Relationship of fragment size to normalized spall strength for materials. Int J Impact Eng 10:107-124

23. Gray GT III, Bourne NK, Henrie BL, Millett JCF (2003) Influence of shock-wave profile shape (triangular-"Taylor-wave" versus square-topped) on the spallation response of $316 \mathrm{~L}$ stainless steel. J Phys IV France 110:773

24. Gray III GT, Livescu V, Rigg PA, Trujillo CP, Cady CM, Chen SR, Carpenter JS, Lienert TJ, Fensin S (2015) Structure/property (constitutive and dynamic strength/damage) characterization of additively manufactured 316L SS. Proceedings of the 11th international conference on the mechanical and physical behaviour of materials under dynamic loading (DYMAT), vol 94. The European Physical Journal, Lugano

25. Sencer BH, Maloy SA, Gray GT III (2005) The influence of shock-pulse shape on the structure/property behaviour of copper and 316L austenitic stainless steel. Acta Mater 53:3293-3303
26. Pavlenko AV, Malyugina SN, Kazakov DN, Zuev YN, Shestakov AE, Belyaev DA (2011) Plastic deformation and spall fracture of structural $12 \mathrm{Cr} 18 \mathrm{Ni} 10 \mathrm{Ti}$ steel. Proceedings of the SCCM conference. American Institute of Physics, Melville

27. Meyers MA (1994) Dynamic behaviour of materials. Wiley, New York

28. Bourne NK (2013) Materials in mechanical extremes. Cambridge University Press, Cambridge

29. Hall EO (1951) The deformation and ageing of mild steel: III. Discussion of results. Proc Phys Soc Lond Sect B 64(9):747-753

30. Guo W-G, Nemat-Nasser S (2006) Flow stress of Nitronic-50 stainless steel over a wide range of strain rates and temperatures. Mech Mater 38:1090-1103

31. Gray III GT, Livescu V, Rigg PA, Trujillo CP, Cady CM, Chen SR, Carpenter JS, Lienert TJ, Fensin S (2015) Structure/property (constitutive and dynamic strength/damage) characterization of additively manufactured $316 \mathrm{~L}$ SS. In: 11 th international conference on the mechanical and physical behaviour of materials under dynamic loading (DYMAT), Lugano, 2015. The European Physical Journal, p 02006

32. Swegle JW, Grady DE (1985) Shock viscosity and the prediction of shock wave rise times. J Appl Phys 58:692

33. Bland DR (1965) On shock structure in a solid. J Inst Math Appl $1: 56-75$

34. Grady DE (2010) Structured shock waves and the fourth-power law. J Appl Phys 107:013506

35. Austin RA, McDowell DL (2011) Parameterization of a ratedependent model of shock-induced plasticity for copper, nickel, and aluminum. Int J Plast 32-33:134-154

36. Malygin GA, Ogarkov SL, Andriyash AV (2013) On the power law pressure dependence of the plastic strain rate of crystals under intense shock wave loading. Phys Solid State 55(4):780-786

37. Millett JCF, Cotton M, Bourne NK, Park NT, Whiteman G (2014) The behaviour of niobium and molybdenum during uniaxial strain loading. J Appl Phys 115:073506

38. Gray GT, Morris CE (1991) Influence of loading paths on the mechanical response and substructure evolution of shock loaded copper. J Phys IV Colloq C3:191-196

39. Gray GT III, Huang JC (1991) Influence of repeated shock loading on the substructure evolution of $99.99 \mathrm{wt} \%$ aluminum. Mater Sci Eng A 145:21-35

40. Gray GT, Hayes DB, Hixson RS (2000) Influence of the shock induced a-e transition in $\mathrm{Fe}$ on its post-shock substructure evolution and mechanical behavior. J Phys IV 10:755-760

41. Mahajan S, Bartlett AF (1971) Influence of prior mechanical and thermal treatments on shock-induced substructures in molybdenum. Acta Metall 19:1111-1119

42. Murr LE, Inal OT, Morales AA (1976) Direct observation of vacancies and vacancy-type defects in molybdenum following uniaxial shock-wave compression. Acta Metall 24:261-270

43. Gray GT III, Cady CM, McCabe RJ, Hixson RS, Korzekwa DR, Lopez MF (2006) Influence of energetic-driven "Taylor-Wave" shock-wave prestraining on the structure property response of depleted uranium. J Phys IV France 134:909-914

44. Smallman RE (1985) Modern physical metallurgy. Butterworths, London 